\title{
Cork based composites using polyolefin's as matrix: Morphology and mechanical performance
}

\author{
Emanuel M. Fernandes ${ }^{\mathrm{a}, \mathrm{b}, *}$, Vitor M. Correlo ${ }^{\mathrm{a}, \mathrm{b}}$, José A.M. Chagas ${ }^{\mathrm{c}}$, João F. Mano ${ }^{\mathrm{a}, \mathrm{b}}$, Rui L. Reis ${ }^{\mathrm{a}, \mathrm{b}, *}$ \\ a 3B's Research Group - Biomaterials, Biodegradables and Biomimetics, Department of Polymer Engineering, University of Minho, AvePark, Zona Industrial da Gandra, \\ S. Cláudio do Barco, 4806-909 Caldas das Taipas, Guimarães, Portugal \\ ${ }^{\mathrm{b}}$ IBB - Institute for Biotechnology and Bioengineering, Associated Laboratory, Braga, Portugal \\ ${ }^{c}$ Amorim Revestimentos, S.A., Rua do Ribeirinho No. 202, P.O. Box 13, 4536-907 S. Paio de Oleiros, Portugal
}

\section{A R T I C L E I N F O}

\section{Article history:}

Received 13 April 2010

Received in revised form 14 September

2010

Accepted 17 September 2010

Available online 25 September 2010

\section{Keywords:}

Cork and thermoplastic

A. Coupling agents

B. Mechanical properties

B. Thermal properties

E. Pultrusion

\begin{abstract}
A B S T R A C T
The cork industry produces high amounts of cork powders resulting from the final stages of cork processing or resulting from existing cork products. Usually these powders are burned and served to boilers in industrial processes. The main goal of this work is to transform this cork sub-product into a highly value composite product. The real value is dependent on the mechanical performance of this product. Thus the mixture between cork and thermoplastics, particularly the improvement of interfacial bonding, is an important topic, which needs to be developed. The interfacial affinity can be greatly increased, applying superficial modification of one of the components, or by the use of coupling agents. In this work, a high amount of cork powder (50 wt.\%) from different origins combined with different thermoplastic materials using melt based processes has been examined. Pultrusion was used to produce pellets and compression moulding to obtain boards to determine its properties. Coupling agents based on maleic anhydride (2 wt.\%) improved the tensile strength successfully, while the cork powder has an a important role in the stiffness. The morphology of the surface fractures indicated a good dispersion of the cork and a good adhesion between both phases. Thermal properties of the composites disclosed a nucleating effect promoted by cork.
\end{abstract}

(c) 2010 Elsevier Ltd. All rights reserved.

\section{Introduction}

Cork is the outer bark of an oak tree known botanically as Quercus suber L. which is periodically extracted from the tree, usually every 9-12 years, depending on the culture region [1-3]. Cork presents a homogeneous tissue of thin-walled cells, regularly arranged without intercellular space $[3,4]$. The cells are rectangular prisms, mostly pentagonal and hexagonal like a honeycomb structure (see Fig. 1), with their axes along the tree's radial direction, stacked in columns $[4,5]$. Like wood, cork is a lignocellulosic material were suberin an aliphatic polyester is the main chemical component of cork cell walls $30-50 \%[2,6,7]$ that is not present in wood cell walls. This anisotropic material has a unique combination of properties, such as a high coefficient of friction [8], resilience, imperviousness to liquids (excellent sealing ability), low thermal conductivity, low density [1], high energy absorption, excellent insulation properties, near-zero Poisson coefficient [9], fire resistant, among others, that

* Corresponding authors. Address: 3B's Research Group - Biomaterials, Biodegradables and Biomimetics, University of Minho, AvePark, Zona Industrial da Gandra, 4806-909 Caldas das Taipas, Portugal. Tel.: +351 253 510900; fax: +351 253 510909.

E-mail addresses: efernandes@dep.uminho.pt (E.M. Fernandes), rgreis@dep. uminho.pt (R.L. Reis). makes it a adequate material for a variety of applications $[3,5,10]$ Every second, an area of rain forest corresponding to 19 tennis courts is lost [11], where the cork-tree offers the advantage of remain the only tree whose bark can regenerate itself after harvest, it is truly a renewable, environmentally friendly resource $[2,12]$.

The most important sub-product provided from the different processes of cork industry is the cork powder, which possesses a high heating value, serving as raw material to feed the boilers in industrial processes $[3,13]$ but its commercial value is insignificant. There exist diverse types of cork powders that present different features. The most important are: the grinding powder, from granulation or pre-grinding; the cleaning powder, without impurities; the finishing powder from cut and sanding operations or from cork disks and natural stoppers and finally the "burning powder" that comes from the mixture of these powders [13]. The degradation of cork is strongly dependent on temperature and mass losses become significant at $200{ }^{\circ} \mathrm{C}$ [14] and the colour start to change to dark brown and at $300^{\circ} \mathrm{C}$ to black [15]. At lower temperatures $75-85^{\circ} \mathrm{C}$, only a phase transition was assigned to the melting of waxes present in cork obtained by DSC that was corroborated by dielectric spectroscopy $[16,17]$.

The aesthetical nature, the touch and the feeling of comfort promoted by the cork is also valued in several applications $[18,19]$ 


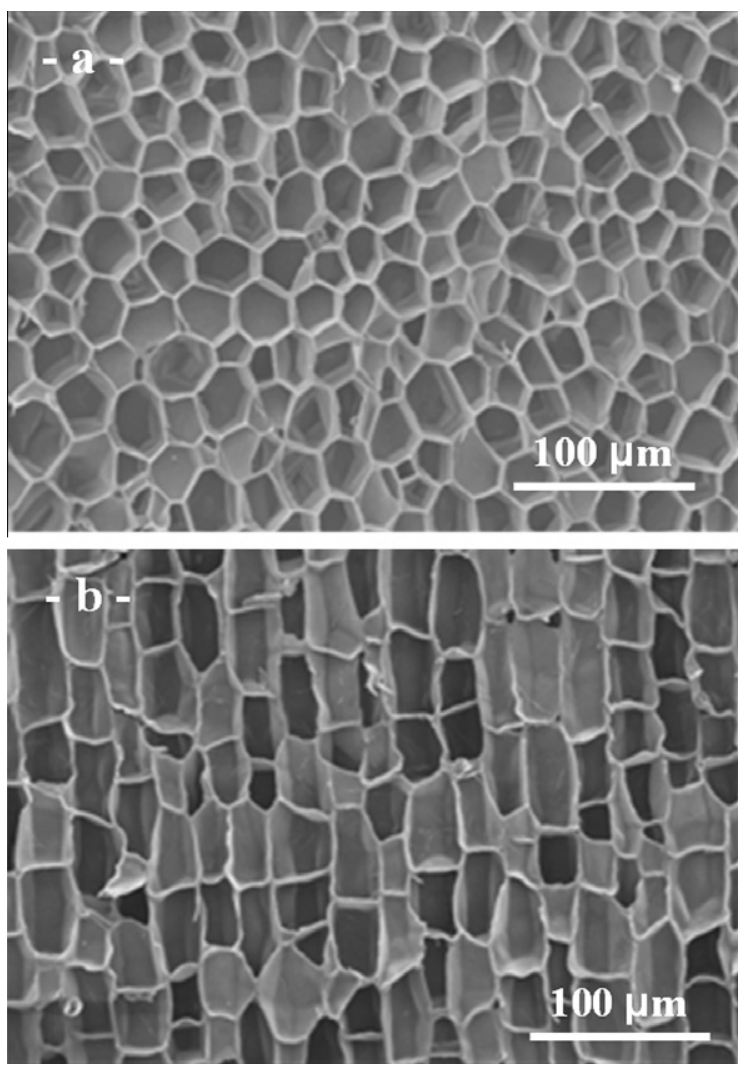

Fig. 1. Cork morphology according: (a) radial direction and (b) non-radial directions.

were its combination with other materials can improve their performance.

Cork combined with polymers leads to composites with novel properties and presents a new field of applications that contributes for the sustainability of the forestry sector. Cork-polymer composite $(\mathrm{CPC})$ materials intend to combine the engineering properties of the thermoplastics with the unique described advantages of this natural origin material trough appropriated melt based technologies in order to develop products with new shapes from theses that cork can provide for acoustic, thermal insulation, energy absorbing or aesthetic applications. Earlier the industry saw in this natural material potential to be used in melt based technologies like extrusion [20-22] or to create a wood substitute material [22]. In a study performed by Barlow and Ashby [23], cork powders were mixed with different binding agents with a thermoplastic, a thermoset and a silicone rubber matrixes to create CPC. The mechanical performance of the composites decreases with the increase of cork content.

In the last years there was an increasing interest on the CPC materials [24-27] for different uses. Another study combines polypropylene with cork that was previously submitted to a surface modification to improve cork-matrix adhesion, based on a water treatment at room temperature during 1-3 h [28] and more recently some applications are looking to the valorisation of the cork powders [29-31]. The improvement of interfacial bonding, between the cork and the matrix is a field that needs to be further developed, for example by using superficial modification of one of the components or by the use of coupling agents. In other polymeric composites based on wood several studies propose different strategies to increase the interfacial adhesion between the different composite phases [32,33]. The use of these kinds of methodologies has been scarce in materials containing cork.
In this study, cork powder with different qualities were mixed in high amounts (50 wt.\%), and were compounded with thermoplastic materials in a pultrusion system to create CPC pellets. These pellets were compressed moulded to obtain boards with a high dimensional stability. The effect of two coupling agents based on a low percentage ( $2 \mathrm{wt} . \%$ ) of maleic anhydride was analysed. The coupling agents were applied to promote adhesion between the cork-polyolefin phases, to improve tensile strength and the cork dispersion.

\section{Materials and methods}

\subsection{Cork materials}

Several cork powders, from cork processing stages were collected at the Amorim Revestimentos S.A. (Portugal) industrial facilities. All of them are cork based powders coming from the processing industries namely, grinding powder, or sanding powder, external powder, cork style powder and floating powder, with density raging from 157 to $400 \mathrm{~kg} \mathrm{~m}^{-3}$.

Grinding powder is mainly composed by the outer bark. This sub-product is characterized by having high density and dark brown colour (Fig. 2), resembling the wood bark in its visual aspect. Moreover, this powder presents contaminations with silica from the sandpaper, resins, varnish and paint pigments due to the incorporation of materials for recycling. Sanding/external powder is mainly composed of cork particles of good quality and low density. It may also present some contaminations with resins from the agglomeration glues and glue from the decorative process and some silica from the sandpaper but in very low amounts. Corkstyle ${ }^{\circledR}$ powder is composed of high density fibreboard (HDF) formed during the machining process of the dock and cork, with a greater amount of HDF powder. The density is very similar compared with the floating powder. Floating powder consists of cork and HDF particles. Polyvinyl chloride (PVC) particles are also presents in small amounts. Some varnish, paint pigments, resin and sinter bonding motifs may be present.

\subsection{Polymer materials and coupling agents}

A commercially available polyethylene (HMA - 025), PE, with a

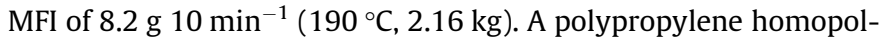
ymer (1374 E2), PP, with a MFI of $20.8 \mathrm{~g} 10 \mathrm{~min}^{-1}\left(20{ }^{\circ} \mathrm{C}, 2.16 \mathrm{~kg}\right.$ ). Both polymers were supplied by Exxon Mobil (Germany). A mixture of recycled polyolefins in the grinding form with a MFI of $2.4 \mathrm{~g} 10 \mathrm{~min}^{-1}\left(190{ }^{\circ} \mathrm{C}, 2.16 \mathrm{~kg}\right)$, provided by Pallmann Maschinenfabrik $\mathrm{GmbH}$ and Co., Germany was also used for the preparation of composites. All tests of melt flow index were carried out according to ISO 1133. Two different coupling agents based on maleic anhydride were used: 102-1 K1 MDEX for polyethylene and Po 1020 K1 for polypropylene respectively, supplied by A. Schulman $\mathrm{GmbH}$, Germany.

\subsection{Composites processing}

The different cork powders were mixed with the thermoplastics (in 50-50 wt.\% ratio) in the dry form and further compounded in an industrial pultrusion system (Palltruder PFV 250, Germany) to obtain cork-polymer composite pellets (Pallmann Maschinenfabrik $\mathrm{GmbH}$ and Co., Germany). Before compounding all raw materials were pre-dried at $70{ }^{\circ} \mathrm{C}$ over night to stabilise the cork powders in terms of moisture content.

The prepared compositions and processing conditions are summarized in Table 1. In a further step, compression moulding of the obtained pellets using a hydraulic press from (Moore, UK) was 

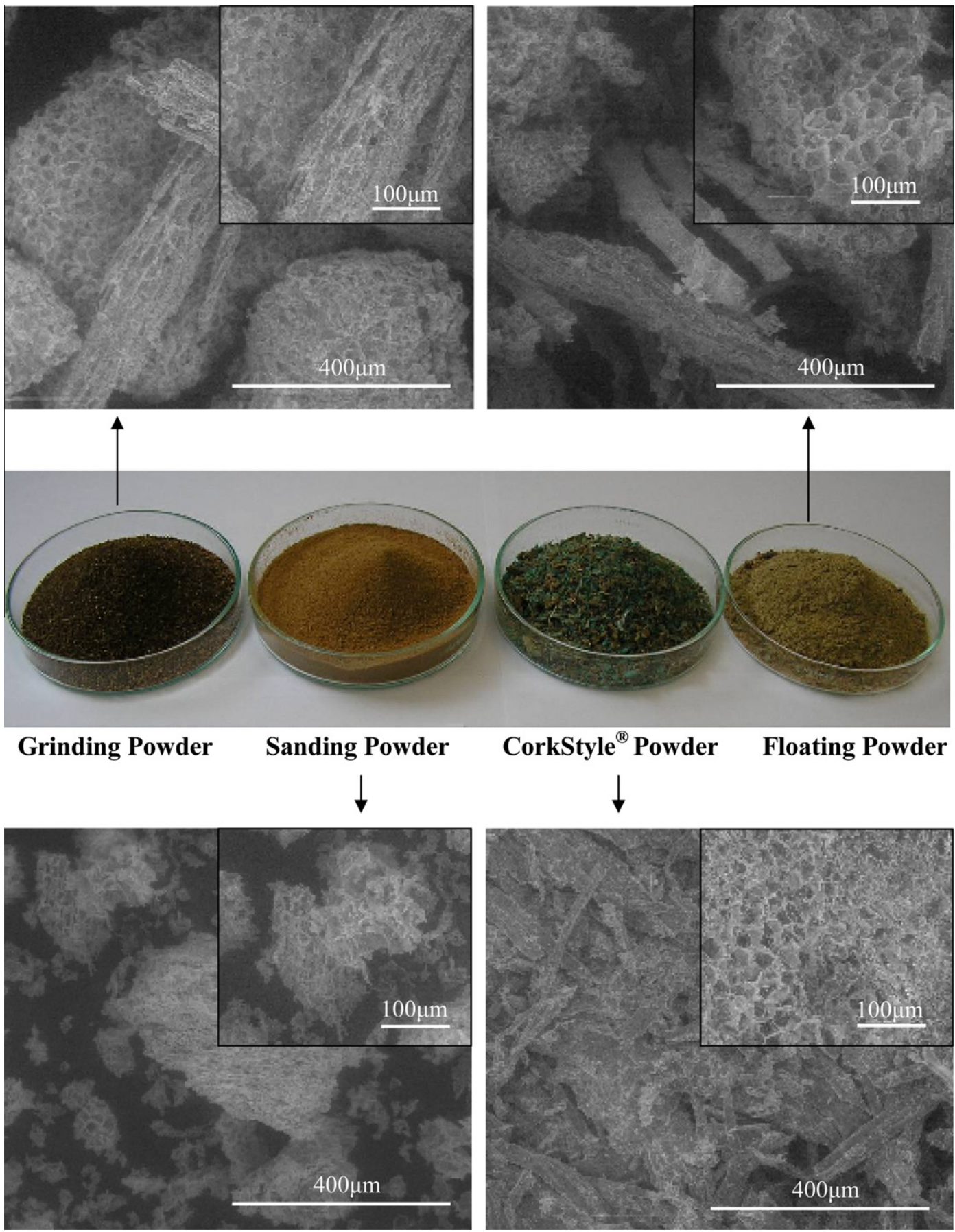

Fig. 2. Ambiental scanning electron micrographs of each cork powder quality provide from the different steps of cork industrial process used to produce the CPC.

applied to produce boards with $3 \mathrm{~mm}$ of thickness from the different compositions. The mould temperature was around $150-170{ }^{\circ} \mathrm{C}$ depending on the thermoplastic matrix and the pressure was 1.42 MPa. Tensile bars were obtained from these boards using a CNC machine (Roland 3D Plotter MDX-20, UK). The specimens had a neck cross-section area of $3 \mathrm{~mm} \times 4 \mathrm{~mm}$ and a gage length of $20 \mathrm{~mm}$. The specimens were produced according ISO 527-2. Nevertheless, its thickness is slightly higher $(3 \mathrm{~mm})$ than the standard.

\subsection{Cork and pellets density and humidity}

\subsubsection{Cork density}

The bulk density of the different cork powders was determined using a volumetric flask of $500 \mathrm{ml}$ were it was placed and com- pacted the material to minimise the possible empty spaces between the particles.

$d=\frac{m}{v}$

The Eq. (1) was applied for density calculations were, $d$ is the specific weight $\left(\mathrm{kg} / \mathrm{m}^{3}\right)$ of the cork raw material, $m$ is the weight of the compact cork powder and $v$ is the volume occupied by the cork powder into the volumetric flask. Three measurements were performed for each cork powder. The specific weight results and respective standard deviation are presented in Table 2.

\subsubsection{Pellets apparent density}

The apparent density of the different composite pellets, obtained after pultusion, was determined using the liquid 
Table 1

Processing conditions used for various blend and composite compositions studied.

\begin{tabular}{|c|c|c|c|c|c|c|c|}
\hline \multirow[t]{2}{*}{ Code } & \multirow[t]{2}{*}{ Cork powder } & \multirow[t]{2}{*}{ Polymer } & \multirow[t]{2}{*}{ Coupling agent (wt.\%) } & \multirow[t]{2}{*}{ Composite (wt.\%) } & \multicolumn{3}{|c|}{ Pultrusion conditions } \\
\hline & & & & & Temperature $\left({ }^{\circ} \mathrm{C}\right)$ & Motor current (A) & Pellets humidity (\%) \\
\hline PP-GP 1 & Grinding & $\mathrm{PP}$ & - & $50-50$ & 160 & 150 & 0.90 \\
\hline $\mathrm{PP}-\mathrm{GP}_{2}$ & Grinding & & 2 & 49-49 & 160 & 150 & 1.00 \\
\hline $\mathrm{PP}_{-\mathrm{SP}_{1}}$ & Sanding & & - & $50-50$ & 170 & 120 & 0.20 \\
\hline $\mathrm{PP}-\mathrm{SP}_{2}$ & Sanding & & 2 & 49-49 & 170 & 120 & 0.50 \\
\hline PP-EP 1 & External & & - & $50-50$ & 150 & 120 & 0.20 \\
\hline $\mathrm{PP}-\mathrm{EP}_{2}$ & External & & 2 & $49-49$ & 150 & 120 & 0.20 \\
\hline $\mathrm{PP}-\mathrm{CSP}_{1}$ & Cork style & & - & $50-50$ & 160 & 130 & 0.50 \\
\hline $\mathrm{PP}-\mathrm{CSP}_{2}$ & Cork style & & 2 & 49-49 & 165 & 130 & 0.30 \\
\hline $\mathrm{PP}-\mathrm{FP}_{1}$ & Floating & & - & $50-50$ & 150 & 120 & 0.20 \\
\hline $\mathrm{PP}-\mathrm{FP}_{2}$ & Floating & & 2 & 49-49 & 160 & 120 & 0.20 \\
\hline RP-SP ${ }_{1}$ & Sanding & Recycled & - & $50-50$ & 150 & 130 & 0.35 \\
\hline $\mathrm{PE} \mathrm{SP}_{1}$ & Sanding & HDPE & - & $50-50$ & 150 & 135 & 0.20 \\
\hline PE-SP ${ }_{2}$ & Sanding & & 2 & 49-49 & 140 & 120 & 0.20 \\
\hline${\mathrm{PE}-\mathrm{EP}_{1}}_{1}$ & External & & - & $50-50$ & 135 & 130 & 1.01 \\
\hline $\mathrm{PE}-\mathrm{EP}_{2}$ & External & & 2 & 49-49 & 135 & 130 & 0.35 \\
\hline PE-CSP 1 & Cork style & & - & $50-50$ & 140 & 130 & 0.30 \\
\hline PE-CSP 2 & Cork style & & 2 & 49-49 & 130 & 125 & 0.30 \\
\hline PE-FP 1 & Floating & & - & $50-50$ & 130 & 130 & 0.35 \\
\hline PE-FP 2 & Floating & & 2 & 49-49 & 130 & 125 & 0.40 \\
\hline
\end{tabular}

Table 2

Type of cork powders and their characteristics in terms of distribution size, specific weight and the percentage of moisture, used for preparing cork based composites.

\begin{tabular}{lllll}
\hline $\begin{array}{l}\text { Granulometry mesh } \\
(\mathrm{mm})\end{array}$ & \multicolumn{4}{l}{ Quality of cork residue } \\
\cline { 2 - 5 } & $\begin{array}{l}\text { Floating } \\
(\%)\end{array}$ & $\begin{array}{l}\text { Corkstyle } \\
(\%)\end{array}$ & $\begin{array}{l}\text { Grinding } \\
(\%)\end{array}$ & $\begin{array}{l}\text { Sanding/ } \\
\text { external }(\%)\end{array}$ \\
\hline$>4$ & 1 & 0.4 & 0 & 0 \\
$2.8-4$ & 1.9 & 2.6 & 0 & 0 \\
$2-2.8$ & 4 & 8.1 & 0.2 & 0 \\
$1-2$ & 10.2 & 2.2 & 0.3 & 0.7 \\
$0.5-1$ & 10.3 & 22.1 & 42.9 & 7.6 \\
$0.25-0.5$ & 14.2 & 13.1 & 34.2 & 3.5 \\
$<0.25$ & 58.4 & 26.5 & 22.4 & 61.2 \\
Sum & 100 & 100 & 100 & 100 \\
Specific weight & $256 \pm 7$ & $273 \pm 6$ & $409 \pm 6$ & $157 \pm 2$ \\
$\quad\left(\mathrm{~kg} / \mathrm{m}^{3}\right)$ & & & & \\
Initial humidity (\%) & $5.8 \pm 0.4$ & $6.4 \pm 0.1$ & $18.0 \pm 0.3$ & $5.4 \pm 0.1$ \\
After drying & $2.7 \pm 0.3$ & $3.5 \pm 0.2$ & $4.2 \pm 0.2$ & $3.2 \pm 0.1$ \\
$\quad$ humidity & & & \\
\hline
\end{tabular}

${ }^{\text {a }}$ Humidity\% present after dry in a vacuum oven during overnight at $70{ }^{\circ} \mathrm{C}$.

displacement method based on the Archimedes principle. By this method, the volume of the sample is estimated by the mass of the volume that is displaced when the sample is submerged in a liquid. Thus, cork-polymer pellet samples weighting between 7 and $11 \mathrm{~g}$ (the weight was determined with a precision nearest to $0.0001 \mathrm{~g}$ ) were it was added distillate water to fulfil the empty spaces between the pellets. Special care was taken to avoid the presence of air bubbles. This procedure was performed three times for each condition.

\subsubsection{Humidity}

The percentage of humidity of the different cork powders was determined using a balance Sartorius (Sartorius AG, Germany) were the cork powder was submitted to $105^{\circ} \mathrm{C}$ during a period of $10 \mathrm{~min}$. This procedure was performed three times for each cork powder sample and the results are presented in Table 2.

\subsection{Scanning electron microscopy}

The morphological characterization of the developed corkpolymer composites fracture surface was performed using a Leica-Cambridge S-360 (UK) scanning electron microscope. All the samples were sputter-coated with gold before being analysed. The cork powders were analysed using a Quanta 400 FEG model (FEI, USA) ambiental scanning electron microscope with low vacuum to avoid any possible desire effect in the natural raw material structure.

\subsection{Thermal properties}

The differential scanning calorimetric experiments were performed in a TA instrument DSC Q100 model (USA), using a refrigerated cooling system and nitrogen as a purge gas (flux gas of ca. $50 \mathrm{ml} \mathrm{min}{ }^{-1}$ ). Both temperature and heat flux were calibrated with Indium at a scanning rate of $10^{\circ} \mathrm{Cmin}^{-1}$. The samples were obtained by cutting a small piece of material (with $5-5.5 \mathrm{mg}$ wt.) in the central region of the composite pellets parts. An effort was made to maintain the geometry of the different samples, in order to keep the same thermal resistance. All the experiments were performed at $10^{\circ} \mathrm{C} \mathrm{min}{ }^{-1}$, starting from room temperature. Only the second run was analysed for melting temperature $\left(T_{m}\right)$ and melting enthalpy $\left(\Delta H_{m}\right)$, which reflects the effect of the cork material contained in the composite avoiding the morphology effect developed during the processing. The crystallinity values of the polymeric phase were determined from the cooling cycle using the following equation:

Degree of Crystallinity $(\%)=\left(\Delta H_{f} / \Delta H_{f^{\circ}}\right) \times 100$

where, $\Delta H_{m}$ is the melting enthalpy of the polymer and $\Delta H_{m}$ is the enthalpy of $100 \%$ crystalline PP $\left(\Delta H_{m^{\circ}}=209 \mathrm{~J} / \mathrm{g}\right)$ [34].

\subsection{Optical microscopy}

To understand the nucleating ability of cork on the matrix, a single cork powder was sandwiched between two thin PP films and heated at $200{ }^{\circ} \mathrm{C}$ during $10 \mathrm{~min}$ to erase the previous thermal history of the sample. Then, the sample was quickly shifted to a well-controlled temperature stage (Linkam, THMS-600) where the pre-determined crystallization temperature was maintained at $140{ }^{\circ} \mathrm{C}$ for $1 \mathrm{~h}$, to access to the crystallization process. A fast cooling was estimated to be $80^{\circ} \mathrm{C} \mathrm{min}-1$ was used to reach the isothermal crystallization temperature. Dry nitrogen was introduced to eliminate any possible degradation in all cases. The crystallization of PP on the cork powder was observed on an optical microscope (Olympus B) connected to a Leica digital camera. 

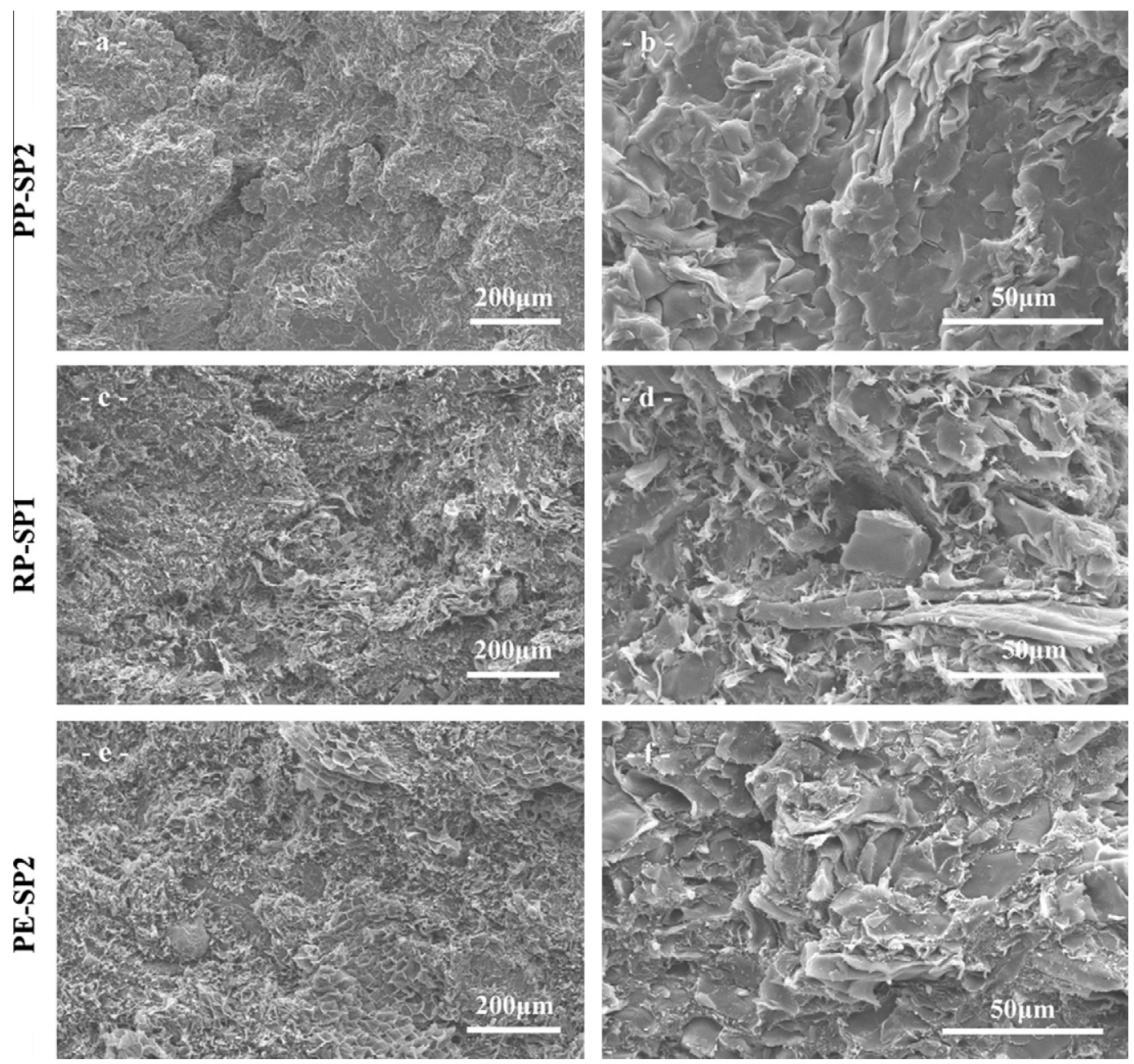

Fig. 3. Morphology of the tensile-fracture surface of cork-polymer composites. (a and b) PP-SP2; (c and d) RP-SP1; (e and f) PE-SP2.

\subsection{Mechanical properties and statistical analysis}

The tensile properties were determined using a Universal tensile testing machine (Instron 4505 Universal Machine, USA) using a load cell of $1 \mathrm{kN}$. The tensile force was taken as the maximum force in the force deformation curve. Tensile modulus was estimated from the initial slope of the stress-strain curve (between $0.05 \%$ and $1 \%$ strain) using the linear regression method. Samples were conditioned at room temperature for at least $48 \mathrm{~h}$ before testing. A crosshead speed of $5 \mathrm{~mm} \mathrm{~min}^{-1}$ was used up to a deformation at break. The average and standard deviations were determined using seven specimens. The normality of the distribution of the mechanical results was evaluated using Shapiro-Wilk test confirming their normal distribution at $p<0.05$. The results were compared using a two-sample $t$-test and differences were considered significantly different at $p<0.05(*)$.

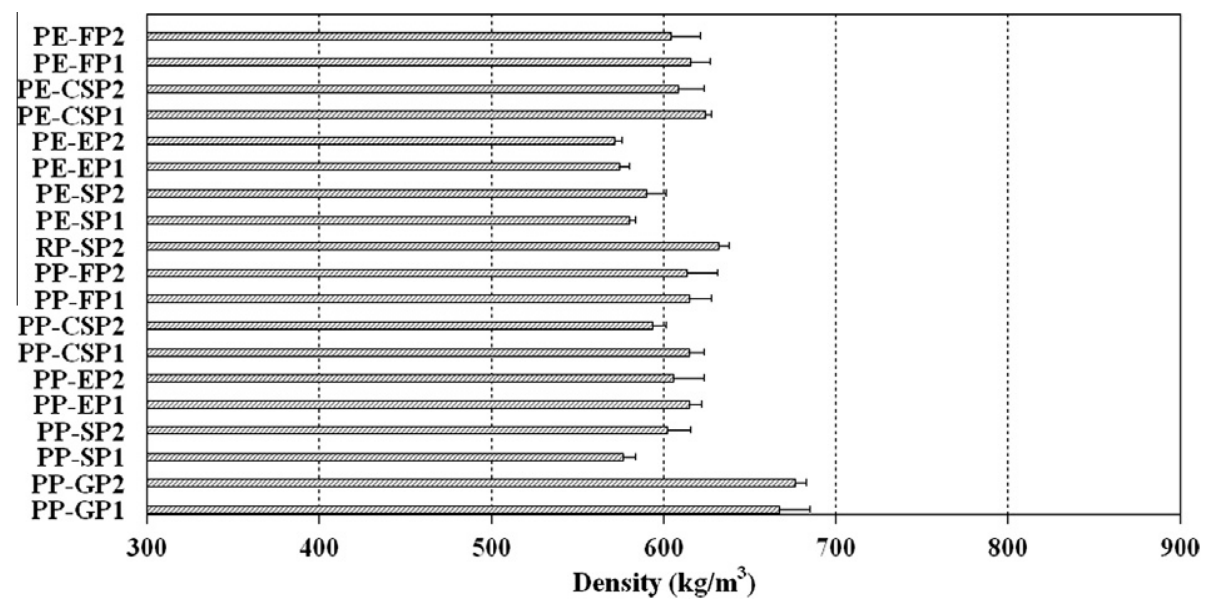

Fig. 4. Density of the $\mathrm{CPC}$ pellets after the pultrusion process. 

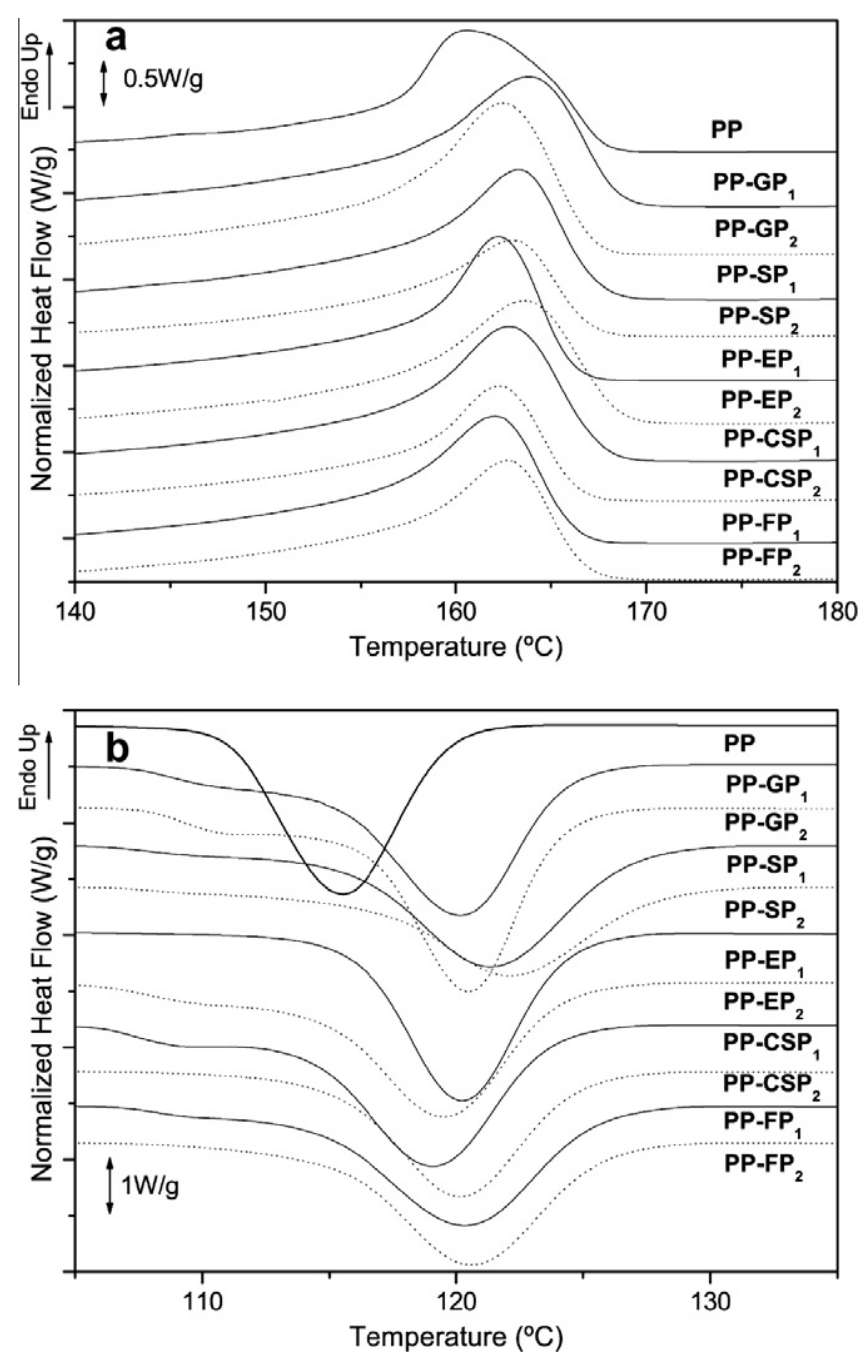

Fig. 5. Representative DSC thermograms, obtained at $10^{\circ} \mathrm{Cmin}^{-1}$ of the $\mathrm{CPC}$ materials using PP as matrix of the composite: (a) second heating step and (b) first cooling step.

\section{Results and discussion}

\subsection{Characterization of the cork powders}

The different cork powders used on this study were physically and morphologically characterized before compounding. The used powders and some of their characteristics are presented in Table 2 and Fig. 2. Since the sanding powder and the external powder are very similar, a mixture of the referred powders was used in the work.

Of the analysed cork powders, the grinding powder was the one with higher specific weight $\left(409 \pm 6 \mathrm{~kg} \mathrm{~m}^{-3}\right)$. This residual powder was also the one with the highest moisture content (18\%) probably due to the presence of the wood present from the outer bark that is more hydrophilic than cork.

The sanding/external powder is the powder with lowest specific weight $\left(157 \pm 2 \mathrm{~kg} \mathrm{~m}^{-3}\right)$ and lower range of particle size distribution ( $60 \%$ of particle size less than $0.25 \mathrm{~mm}$ ). This material was also the one presenting the lowest humidity (around 5.4\%).

The Corkstyle ${ }^{\circledR}$ powder and the floating powder presents a specific weight of $273 \pm 6 \mathrm{~kg} \mathrm{~m}^{-3}$ and $256 \pm 7 \mathrm{~kg} \mathrm{~m}^{-3}$ respectively. In terms of humidity the values are very similar and regarding the particle size distribution, the floating powder has a higher content of small particles (around 58\%) less than $0.25 \mathrm{~mm}$.

Table 2 also reports the humidity present in the different powders before the preparation of the composite materials. Since the cork sub-products tend to absorb moisture, all the natural raw materials were pre-dried overnight in a vacuum oven to stabilize. The percentage of humidity present was around $2.65-4.18 \%$.

\subsection{Composite morphology}

Fracture surfaces after mechanical tests of the cork-polymer composites, obtained by scanning electron microscopy, are shown in Fig. 3. In the micrographs is possible to observe the good dispersion of cork sanding powder in the different thermoplastic matrixes. At high magnifications the fracture surface of cork sanding powder with PP and 2 wt.\% of coupling agent (Fig. 3b) indicates good adhesion between both phases of the composite. The same behaviour was observe for the PE matrix (Fig. 3e and f); while the cork sanding powder mixture with the recycled polymers at a high magnifications (Fig. 3d) demonstrate some pull out of the polymeric phase and some regions with gap between both phases. This may be due to the lower mechanical properties of this matrix since is a mixture of different grade of recycled plastics that could contain some impurities and due to the absence of coupling agent to improve the interface bonding.

\subsection{Pellets density}

Fig. 4 indicates the apparent density of the cork-polymer composite pellets after the pultrusion process for all tested compositions presented in Table 1 . The results indicates an important decrease in the density compared with the density of the matrix PE $\left(964 \mathrm{~kg} \mathrm{~m}^{-3}\right)$ and PP $\left(900 \mathrm{~kg} \mathrm{~m}^{-3}\right)$.The pellets density are around $580-630 \mathrm{~kg} \mathrm{~m}^{-3}$ except for grinding cork powder with

Table 3

Melting temperatures and enthalpies, crystallization temperatures and crystallinity degrees of CPC composites with PP as matrix.

\begin{tabular}{|c|c|c|c|c|c|c|}
\hline Sample & $T_{c}^{\mathrm{a}}\left({ }^{\circ} \mathrm{C}\right)$ & $\Delta H_{c}^{\mathrm{a}}(\mathrm{J} / \mathrm{g})$ & $\chi_{c}{ }^{\mathrm{c}}(\%)$ & $T_{m}{ }^{\mathrm{b}}\left({ }^{\circ} \mathrm{C}\right)$ & $\Delta H_{m}{ }^{\mathrm{b}}(\mathrm{J} / \mathrm{g})$ & $\chi_{c}{ }^{\mathrm{c}}(\%)$ \\
\hline PP & 119.7 & 99.1 & 70.8 & 153.5 & 91.5 & 65.3 \\
\hline PP-GP 1 & 124.3 & $57.2(114.4)$ & $40.9(81.8)$ & 155.0 & $55.3(110.6)$ & 39.5 (79.0) \\
\hline PP-GP 2 & 124.2 & $61.8(126.1)$ & $44.2(86.6)$ & 155.2 & $60.5(123.5)$ & $43.2(84.7)$ \\
\hline $\mathrm{PP}_{-\mathrm{SP}_{1}}$ & 126.9 & $51.3(102.6)$ & $36.7(73.4)$ & 155.8 & $50.9(101.8)$ & $36.4(72.8)$ \\
\hline $\mathrm{PP}_{-} \mathrm{SP}_{2}$ & 128.0 & $40.7(83.1)$ & $29.1(57.0)$ & 154.7 & $39.4(80.4)$ & $28.1(55.1)$ \\
\hline $\mathrm{PP}-\mathrm{EP}_{1}$ & 124.4 & $49.6(99.2)$ & $35.4(70.8)$ & 156.8 & $48.7(97.4)$ & $34.8(69.6)$ \\
\hline $\mathrm{PP}-\mathrm{EP}_{2}$ & 124.2 & $54.9(112.0)$ & $39.2(76.8)$ & 155.0 & $52.9(108.0)$ & $37.8(74.1)$ \\
\hline PP-CSP 1 & 124.0 & $55.7(111.4)$ & $39.8(79.6)$ & 155.3 & $53.7(107.4)$ & $38.4(76.8)$ \\
\hline $\mathrm{PP}-\mathrm{CSP}_{2}$ & 124.9 & $43.2(88.2)$ & $30.8(60.4)$ & 156.2 & $42.4(86.5)$ & $30.3(59.4)$ \\
\hline $\mathrm{PP}_{-\mathrm{FP}_{1}}$ & 125.6 & 50.7 (101.4) & $36.2(72.4)$ & 154.2 & $49.4(98.8)$ & $35.3(70.6)$ \\
\hline $\mathrm{PP}-\mathrm{FP}_{2}$ & 126.0 & $48.5(99.0)$ & $34.7(68.0)$ & 155.2 & $47.3(96.5)$ & $33.8(66.3)$ \\
\hline
\end{tabular}

$(\cdot)$ Values divided by the weight proportion of polymer.

a Crystallization temperature and enthalpy at second cooling from the melt at $10{ }^{\circ} \mathrm{C} \mathrm{mm}^{-1}$.

b Melting temperature and enthalpy determined by DSC on the second heating at $10^{\circ} \mathrm{C} \mathrm{mm}^{-1}$.

c Crystallinity degree calculated on the basis of a $\Delta H_{m}$ value of $209 \mathrm{~J} / \mathrm{g}$ for $100 \%$ crystalline PP [35]. 
higher specific weight (see Table 2). The higher the density of the cork powder the superior is the density of the pellet composite. The production of composites by pultrusion process using high amounts of cork powder allows obtaining light weight composite materials. After compression moulding process of the pellets the final density of the composites is higher and very similar (1000$1060 \mathrm{~kg} \mathrm{~m}^{-3}$ ) independently of the cork sub-product used.

\subsection{Crystallization and melting properties}

Thermal properties of all materials prepared were investigated by DSC. Representative DSC curves for the composites and pure
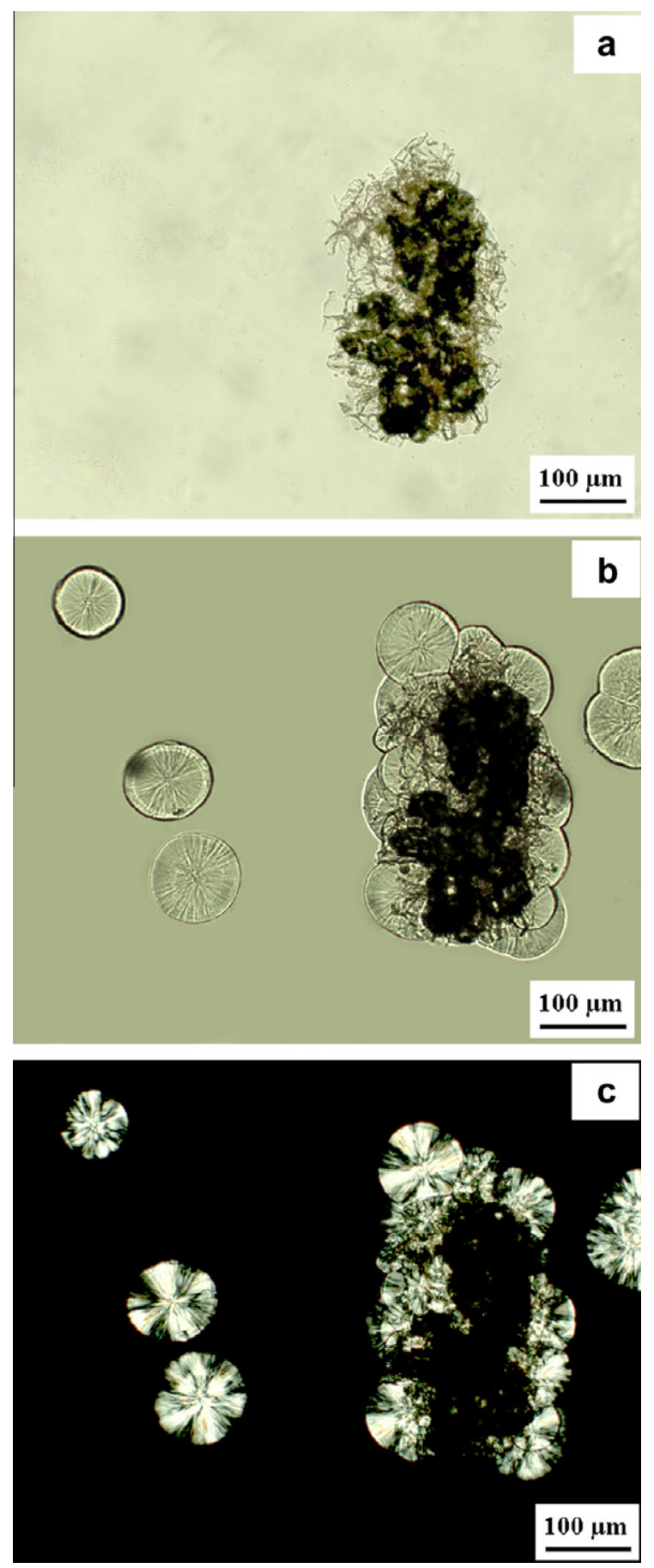

Fig. 6. Optical micrographs showing the crystallization of PP in the presence of cork: (a) $5 \mathrm{~min}$; (b) $45 \mathrm{~min}$ and (c) $45 \mathrm{~min}\left(T_{c}=140^{\circ} \mathrm{C}\right.$, polarized light).
PP are shown in Fig. 5. The results are summarized in Table 3. Pure PP presents a crystallization temperature $\left(T_{c}\right)$ of $119.7^{\circ} \mathrm{C}$. Comparing the pure PP with the cork-polymer composites, the $T_{c}$ shifted to higher temperatures in the case of the composites. The increase of $T_{c}$ could be considered to be due to the nucleation effect of cork present in the composites.

Melting temperatures $\left(T_{m}\right)$ of pure PP was $153.5^{\circ} \mathrm{C}$. The $T_{m} \mathrm{~s}$ of the PP was not significantly affected by the addition of cork during the pultrusion process. Therefore, the addition of cork powders in PP does not have a significant influence on the thickness of the crystalline lamellar of the matrix. Values of $\Delta H_{m}$ provide important information about the crystallinity and shows significant variations in the composites. These results lead us to conclude that the addition of cork powder increases the crystallinity of the polymer in the most part of the compositions.

\subsection{Optical microscopy}

Fig. 6 presents the initial crystallization process of PP in the presence of the cork powder particle. The results suggest that this process takes place preferably at the surface sites of cork. Nevertheless once can observe simultaneously with this process the growth of individual of spherulites in the matrix. When cork is embedded into a thermoplastic melt it may act as a nucleating agent during the crystallization process. The result is more evident in Fig. $6 \mathrm{c}$ in polarized light where it confirms the high number of spherulites around the cork. This nucleation effect is different from other fibres used in composites. In this case no transcrystalline
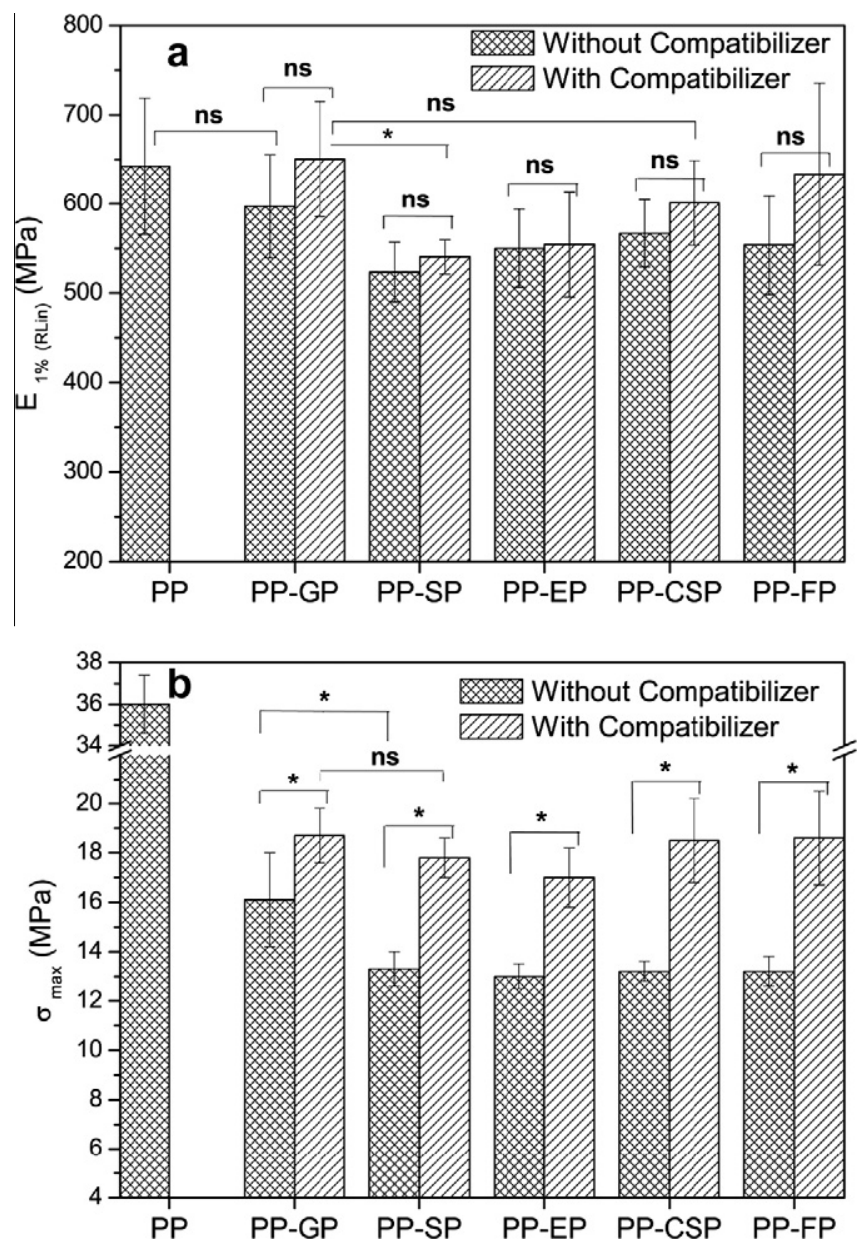

Fig. 7. Tensile properties of various CPC materials using PP as matrix. (*) Significant at 0.05 ; ns: non-significant at 0.05 . 
layer on the cork usually found in semicrystalline thermoplastic composites with different synthetic or natural fibres [35-37] was observed. The present effect it is in accordance with the previous DSC results indicating the nucleation ability of cork.

\subsection{Mechanical properties of composites}

In order to characterize the mechanical performance of the developed cork based composites, tensile tests were performed. Figs. 7 and 8 summarize the obtained results, in terms of tensile modulus and maximum tensile stress, for composites prepared with PP and PE matrices, respectively. One formulation consisting of recycled polyolefin's and cork sanding powder was also compounded and characterized (Fig. 8). All results are expressed as means \pm standard deviation.

Considering the data from both Figs. 7 and 8, it is clear that composites prepared using PP as matrix are the ones with better mechanical performance, being the condition PP-GP1 the one with the highest stiffness and strength absolute values. Two reasons can be used to explain the better performance of this composition: (i) pure PP has better mechanical properties than PE; (ii) the grinding powder (Fig. 2) is mainly composed of the outer bark that is denser and very similar to wood and could work as a more effective reinforcement. In general, composites from PP exhibited mean tensile modulus and maximum stress values respectively in the intervals [523.6-650.5] MPa and [13.0-18.7] MPa, depending on the type of cork powder used. Composites prepared using PE as matrix and the different cork based powders displayed mean compressive modulus and maximum stress values respectively in the intervals
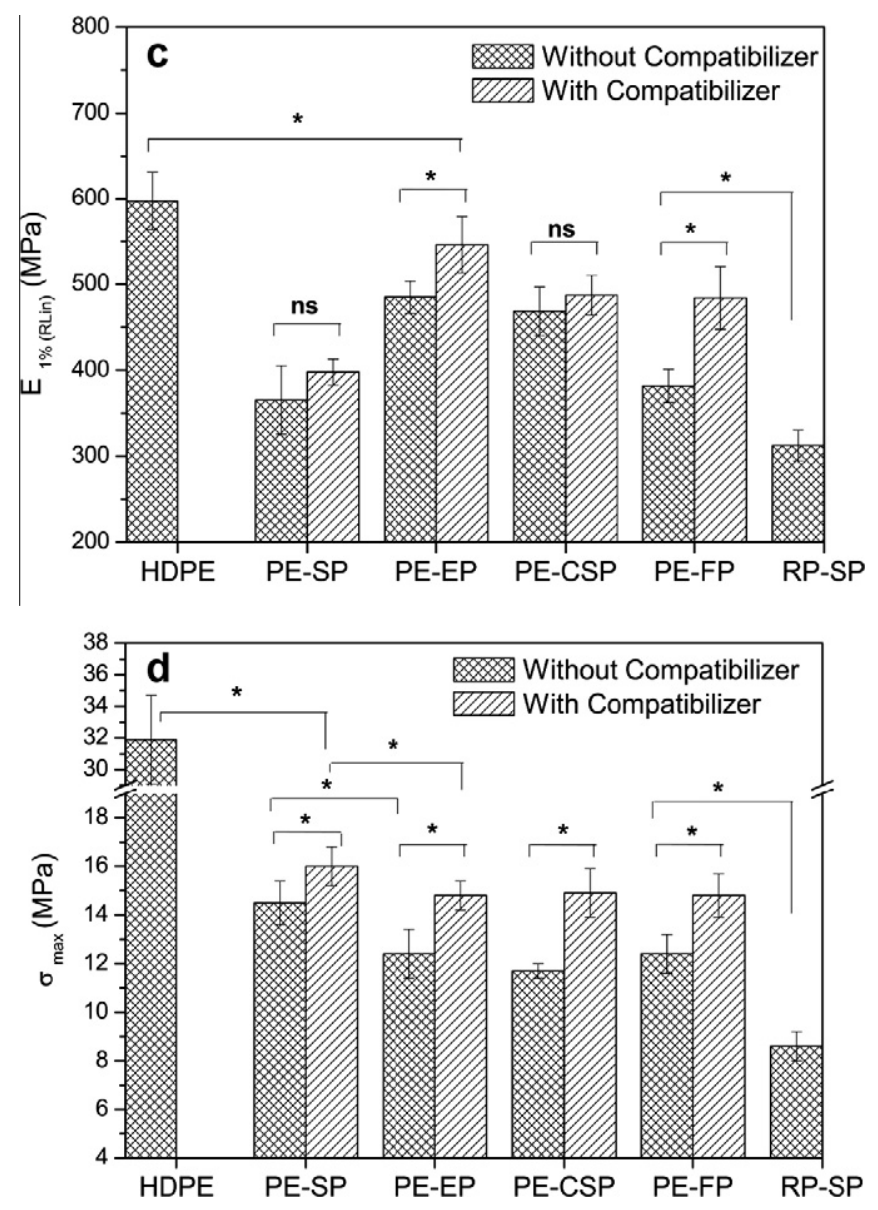

Fig. 8. Tensile properties of various $\mathrm{CPC}$ materials using PE and recycled polymer as matrix. (*) Significant at 0.05 ; ns: non-significant at 0.05 .
[365.3-545.8] MPa and [12.4-16.0] MPa. Almost no correlation between the type of cork powders used and the final mechanical performance of the composites was observed.

Considering the formulation with best performance for each type of matrix used, the addition of $50 \mathrm{wt} . \%$ of cork powder in the most part of the compositions did not affect significantly $(p<0.05)$ the modulus of the final product, especially for the composites prepared with PP. Nevertheless, a decrease higher than $\sim 50 \%$ on the strength was noticed.

As expected, the addition of a small amount (only $2 \mathrm{wt} . \%$ ) of coupling agents (102-1 K1 MDEX for PE and Po 1020 K1 for PP) resulted in a significantly improvement $(p<0.05)$ of the mechanical performance in all the formulations studied. This effect is more pronounced on the strength of composites prepared using PP as matrix and increases up to $40.9 \%$ (condition $\mathrm{PP}_{\mathrm{FP}}$ ) were achieved with the addition of Po $1020 \mathrm{~K} 1$ coupling agent. This is a clear indication that the use of a coupling agent improved the interfacial adhesion between the matrix (PP or PE) and the cork based powder used. Several studies on the literature report the positive effect of using coupling agents on the mechanical properties of composites $[31,33]$.

\section{Conclusions}

The following conclusions can be made base on the results presented in this work. SEM observation revealed well dispersed cork powders in the compression moulded samples after the pultrusion (pellets) and compression moulding processes. As expected, the tensile modulus and tensile strengths were significantly increased in the composites with the introduction low amounts ( $2 \mathrm{wt} . \%$ ) of coupling agents to promote the adhesion between the cork-polymer phases. No significantly correlation between the type of cork powders used and the mechanical performance of the composites was observed. Cork powders that presents some wood particles induces similar stiffness only in the PP matrix, probably because the powder composition is based on outer bark and has higher density. The recycled polymer based on polyolefin's combined with the cork sanding powder reveal the lowest mechanical performance. The increase of the crystallinity on the composites occurred due to the addition of the cork powder, where cork presents a nucleation effect. By polarized optical microscopy it was confirmed that cork accelerates the crystallization process. The results of the present work clearly show that cork powders and polyolefin's can be successfully used to produce CPC with high cork content. In order to obtain cork based composite materials with enhanced mechanical properties, reinforcement strategies must be taken in consideration.

\section{Acknowledgments}

The work presented here was performed within the project of Corticeira Amorim S.G.P.S. on the development of new products based in/with cork. We gratefully acknowledge to Amorim Revestimentos S.A. for the supply of cork materials and also to Pallmann $\mathrm{GmbH}$ for the polymer raw materials and the pultrusion system of the cork-polymer composite pellets.

\section{References}

[1] Gibson LJ. Cellular solids: structure and properties. 2nd ed. Cambridge: Cambridge University Press; 1997.

[2] Gil L, Moiteiro C. Cork. Ullmann's encyclopedia of industrial chemistry. Weinheim: Willey-VCH; 2002.

[3] Silva SP, Sabino MA, Fernandes EM, Correlo VM, Boesel LF, Reis RL. Cork: properties, capabilities and applications. Int Mater Rev 2005;50(6):345-65.

[4] Pereira H, Rosa ME, Fortes MA. The cellular structure of cork from Quercus suber L.. Iawa Bull 1987;8(3):213-8. 
[5] Gibson LJ, Easterling KE, Ashby MF. The structure and mechanics of cork. Proc Roy Soc London A Mater 1981;A377:99-117.

[6] Pereira H. Chemical composition and variability of cork from Quercus suber L.. Wood Sci Technol 1988;22(3):211-8.

[7] Holloway PJ. Some variations in the composition of suberin from the cork layers of higher plants. Phytochemistry 1983;22:495-502.

[8] Vaz MF, Fortes MA. Friction properties of cork. J Mater Sci 1998;33(8):2087-93.

[9] Fortes MA, Nogueira MT. The Poisson effect in cork. Mater Sci Eng A Struct 1989;122(2):227-32.

[10] Pires RA, Mano JF, Reis RL. Surface properties of extracts from cork black condensate. Holzforschung 2010;64:217-22.

[11] Halada K. Progress of ecomaterials toward a sustainable society. Curr Opin Solid Struct Mater 2003;7(3):209-16.

[12] Pereira H. Cork: biology, production and uses. Amsterdam: Elsevier; 2007.

[13] Gil L. Cork powder waste: an overview. Biomass Bioenergy 1997;13(12):59-61.

[14] Pereira H. The thermochemical degradation of cork. Wood Sci Technol 1992;26(4):259-69.

[15] Rosa ME, Fortes MA. Temperature-induced alterations of the structure and mechanical-properties of cork. Mater Sci Eng 1988;100:69-78.

[16] Mano JF. The viscoelastic properties of cork. J Mater Sci 2002;37(2):257-63.

[17] Mano JF, Correia NT, Ramos JJM, Saramago B. The molecular relaxation mechanisms in cork as studied by thermally stimulated discharge currents. J Mater Sci 1995;30(8):2035-41.

[18] Farag MM. Quantitative methods of materials substitution: application to automotive components. Mater Des 2008;29(2):374-80.

[19] Matos MJ, Simplício MH. Innovation and sustainability in mechanical design through materials selection. Mater Des 2004;27:74-8.

[20] Improvements in or relating to extrudable compositions. GB 657813 A, Armstrong Cork Co.; 1951.

[21] Improvements in or relating to extrudable cork compositions. GB 646955 A, Armstrong Cork Co.; 1950.

[22] Method of preparing wood substitute. GB 1395105, Idemitsui Kosan Co. Ltd.; 1975.
[23] Barlow CY, Ashby MF. Cork dust composites. In: Proceedings of the riso international symposium on metallurgy and materials science; 1989.

[24] Chong VC. Balls for use in baseball and softball. US 20040142779 A1; 2004

[25] Cosby SA, Kelly M, Van WB. Silicone-cork ablative material. EP 1482163 A2, United Technologies Corp.; 2005.

[26] Antunes PJ, Dias GR, Coelho AT, Rebelo F, Pereira T. Hyperelastic modelling of cork-polyurethane gel composites: non-linear FEA implementation in 3D foot model. 2008; 587-588: 700-705.

[27] Gil L. Cork composites: a review. Mater Des 2009;2:776-89.

[28] Abdallah FB, Cheikh RB, Baklouti M, Denchev Z, Cunha AM. Characterization of composite materials based on PP-cork blends. J Reinf Plast Comp 2006;25(14):1499-506.

[29] Claro JCAR, Valente AJRP. Particle agglomeration process for wood and cork industrial sectors WO 2008/114103 (A1), WO 2008114103 A1. Universidade de Trás-os-Montes e Alto Douro; 2008.

[30] Fernandes EM, Silva VM, Chagas JAM, Reis RL. Cork-polymer composite (CPC) materials and processes to obtain the same. WO2009072914-A1, Amorim Revestimentos, SA; 2009.

[31] Bledzki AK, Reihmane S, Gassan J. Thermoplastics reinforced with wood fillers: a literature review. Polym Plast Technol Eng 1998;37(4):451-68.

[32] Bledzki AK, Faruk O. Creep and impact properties of wood fibre-polypropylene composites: influence of temperature and moisture content. Compos Sci Technol 2004;64(5):693-700.

[33] Bengtsson M, Stark NM, Oksman K. Durability and mechanical properties of silane cross-linked wood thermoplastic composites. Compos Sci Technol 2007;67(13):2728-38.

[34] Yllser GD, Zakir MO, Rzaev EP. Functionalization of isotactic polypropylene with citraconic anhydride. Polym Bull 2007;59:447-56.

[35] Wang C, Liu CR. Transcrystallization of polypropylene composites: nucleating ability of fibres. Polymer 1999;40(2):289-98.

[36] Pompe G, Mäder E. Experimental detection of a transcrystalline interphase in glass-fibre/polypropylene composites. Compos Sci Technol 2000;60(11):2159-67.

[37] Arbelaiz A, Fernández B, Ramos JA, Mondragon I. Thermal and crystallization studies of short flax fibre reinforced polypropylene matrix composites: effect of treatments. Thermochim Acta 2006;440(2):111-21. 